Supplement of Atmos. Chem. Phys., 17, 15167-15180, 2017

https://doi.org/10.5194/acp-17-15167-2017-supplement

(c) Author(s) 2017. This work is distributed under

the Creative Commons Attribution 4.0 License.

(c) (1)

\title{
Atmospheric \\ Chemistry \\ and Physics
}

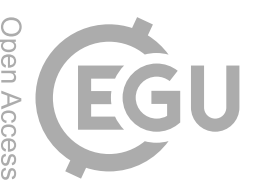

Supplement of

\section{Biogenic, urban, and wildfire influences on the molecular composition of dissolved organic compounds in cloud water}

\author{
Ryan D. Cook et al. \\ Correspondence to: Kerri A. Pratt (prattka@umich.edu)
}

The copyright of individual parts of the supplement might differ from the CC BY 4.0 License. 
22 Table S1. Average August-September total organic carbon (TOC) and sulfate cloud water 23 concentrations at Whiteface Mountain, NY

\begin{tabular}{|c|c|c|}
\hline Year & TOC $\left(\mathbf{m g ~ L}^{-\mathbf{1}}\right)$ & $\mathbf{S O}_{4}{ }^{2-}(\boldsymbol{\mu M})$ \\
\hline 2010 & 4.09 & 53.7 \\
\hline 2011 & 3.15 & 47.7 \\
\hline 2012 & 4.16 & 54.2 \\
\hline 2013 & 3.00 & 45.8 \\
\hline 2014 & 3.06 & 32.3 \\
\hline 2015 & 4.18 & 50.5 \\
\hline
\end{tabular}


25 Table S2. Cloud water sample TOC after SPE concentration $\left(\mathrm{TOC}_{1}\right)$ and after dilution 26 (TOC $\left._{2}\right)$, prior to ESI-FT-ICR analysis

\begin{tabular}{|c|c|c|}
\hline Sample ID & $\mathrm{TOC}_{1}\left(\mathrm{mg} \mathrm{L}^{-1}\right)$ & $\mathrm{TOC}_{2}\left(\mathrm{mg} \mathrm{L}^{-1}\right)$ \\
\hline A1 & 15 & 15 \\
\hline A2 & 32 & 32 \\
\hline A3 & 42 & 42 \\
\hline B1 & 37 & 37 \\
\hline B2 & 45 & 45 \\
\hline C1 & 361 & 30 \\
\hline C2 & 398 & 30 \\
\hline C3 & 153 & 30 \\
\hline
\end{tabular}

27 
Table S3. Peak assignments of cloud water samples showing the molecular formula (mf) and compound type (ct). This table can be found in "Cook_etal_2017_TableS3.xslx" The columns of the table are described below:

Column 'A' contains the observed peak $m / z[\mathrm{M}-\mathrm{H}]$ ' in the mass spectra;

Column ' $\mathrm{B}$ ' contains the $\log _{10}$ of the peak intensity of each assigned compound in sample A1 (0 denotes not identified in sample);

Column ' $\mathrm{C}$ ' contains the $\log _{10}$ of the peak intensity of each assigned compound in sample A2 (0 denotes not identified in sample);

Column ' $\mathrm{D}$ ' contains the $\log _{10}$ of the peak intensity of each assigned compound in sample A3 (0 denotes not identified in sample);

Column 'E' contains the $\log _{10}$ of the peak intensity of each assigned compound in sample B1 (0 denotes not identified in sample);

Column ' $F$ ' contains the $\log _{10}$ of the peak intensity of each assigned compound in sample B2 (0 denotes not identified in sample);

Column ' $G$ ' contains the $\log _{10}$ of the peak intensity of each assigned compound in sample C1

(0 denotes not identified in sample);

Column ' $\mathrm{H}$ ' contains the $\log _{10}$ of the peak intensity of each assigned compound in sample C2 5 (0 denotes not identified in sample);

6 Column 'I' contains the $\log _{10}$ of the peak intensity of each assigned compound in sample C3 4 (0 denotes not identified in sample);

48 Column ' $\mathrm{J}$ ' contains the number of carbon atoms present in the assigned molecular structure 9 of the compounds present;

50 Column ' $\mathrm{K}$ ' contains the number of hydrogen atoms present in the assigned molecular structure 1 of the compounds present;

52 Column ' $\mathrm{L}$ ' contains the number of oxygen atoms present in the assigned molecular structure 3 of the compounds present;

54 Column ' $M$ ' contains the number of nitrogen atoms present in the assigned molecular structure 5 of the compounds present;

6 Column ' $N$ ' contains the number of sulfur atoms present in the assigned molecular structure of 7 the compounds present;

8 Column ' $\mathrm{O}$ ' contains the error (in ppm) between the peak $\mathrm{m} / \mathrm{z}$ and the assigned formula's 59 molecular weight;

60 Column ' $\mathrm{P}$ ' contains the $\mathrm{mf}$ assigned to each peak;

61 Column 'Q' contains the ct classification of the assigned mf. 
62 Table S4. Average hydrogen-to-carbon (H:C) ratios and double bond equivalent (DBE) values, 63 as well as 95\% confidence intervals, for the Whiteface Mountain cloud water negative ion mass 64 spectrometry data

65

\begin{tabular}{|l|c|c|}
\hline \multicolumn{1}{|c|}{ Sample } & H:C & DBE \\
\hline All samples & $1.466 \pm 0.005$ & $6.03 \pm 0.05$ \\
\hline Biogenic (A1-A3) & $1.50 \pm 0.01$ & $5.3 \pm 0.1$ \\
\hline Urban (B1-B2) & $1.504 \pm 0.008$ & $5.96 \pm 0.09$ \\
\hline Wildfire (C1-C3) & $1.427 \pm 0.007$ & $6.34 \pm 0.07$ \\
\hline
\end{tabular}

66 
67 Table S5. Summary of cloud water molecular composition from (-)ESI-FTICR-MS ( $\mathrm{m} / \mathrm{z} 100-1000)$. The average ( \pm 95\% confidence interval) 68 oxygen-to-carbon (O:C) and hydrogen-to-carbon (H:C) ratios, double bond equivalents (DBE), and the number of organic compounds assigned 69 (Total), as well as numbers and percentages by (CHO, CHOS, CHNOS, CHNO) for each sample.

70

\begin{tabular}{cccccccccc}
\hline \multirow{2}{*}{ Event } & \multirow{2}{*}{$\begin{array}{c}\text { Sample } \\
\text { ID }\end{array}$} & \multirow{2}{*}{ O:C } & H:C & DBE & \multicolumn{4}{c}{ Number (\%) } \\
\cline { 6 - 9 } & & & & & CHO & CHOS & CHNOS & CHNO & Total \\
\hline \multirow{3}{*}{ Biogenic } & A1 & $0.47 \pm 0.02$ & $1.51 \pm 0.03$ & $4.97 \pm 0.26$ & $225(53)$ & $61(14)$ & $31(7)$ & $110(26)$ & 427 \\
& A2 & $0.47 \pm 0.01$ & $1.49 \pm 0.02$ & $5.49 \pm 0.19$ & $361(51)$ & $102(14)$ & $63(9)$ & $181(26)$ & 707 \\
& A3 & $0.45 \pm 0.01$ & $1.51 \pm 0.01$ & $5.44 \pm 0.14$ & $397(56)$ & $33(5)$ & $7(1)$ & $272(38)$ & 709 \\
\hline \multirow{2}{*}{ Urban } & B1 & $0.50 \pm 0.01$ & $1.51 \pm 0.01$ & $6.05 \pm 0.11$ & $1008(44)$ & $227(10)$ & $60(3)$ & $981(43)$ & 2276 \\
& B2 & $0.46 \pm 0.01$ & $1.49 \pm 0.01$ & $5.75 \pm 0.13$ & $497(53)$ & $65(7)$ & $39(4)$ & $338(36)$ & 939 \\
\hline \multirow{3}{*}{ Wildfire } & C1 & $0.58 \pm 0.01$ & $1.39 \pm 0.01$ & $6.55 \pm 0.14$ & $712(45)$ & $211(13)$ & $28(2)$ & $644(40)$ & 1595 \\
& C2 & $0.56 \pm 0.01$ & $1.43 \pm 0.01$ & $6.14 \pm 0.14$ & $714(51)$ & $180(13)$ & $19(1)$ & $480(35)$ & 1393 \\
& C3 & $0.47 \pm 0.01$ & $1.46 \pm 0.01$ & $6.32 \pm 0.11$ & $858(47)$ & $93(5)$ & $10(1)$ & $866(47)$ & 1827 \\
\hline
\end{tabular}



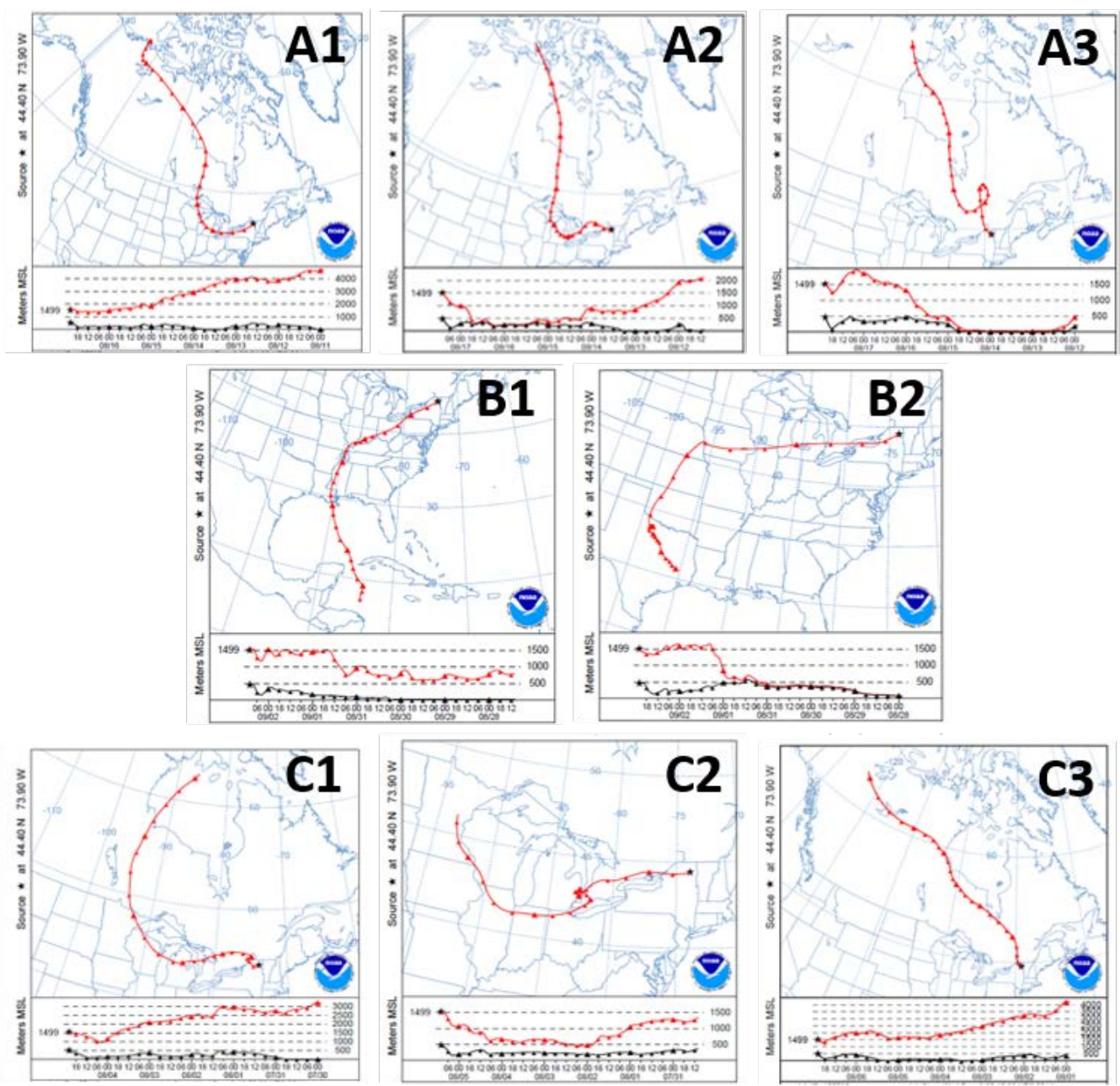

73 Fig. S1. NOAA HYSPLIT $144 \mathrm{~h}$ (6 day) backward air mass trajectory analysis at $1499 \mathrm{~m}$

74 (red line) above mean sea level (MSL) in $6 \mathrm{~h}$ intervals for the cloud water samples collected on (A1-3) August 16-17, 2014, (B1-2) September 2, 2014, and (C1-3) August 4-6, 2014. 
- $\mathrm{CHO}$ - $\mathrm{CHNO}$ - $\mathrm{CHOS}$ and $\mathrm{CHNOS}$
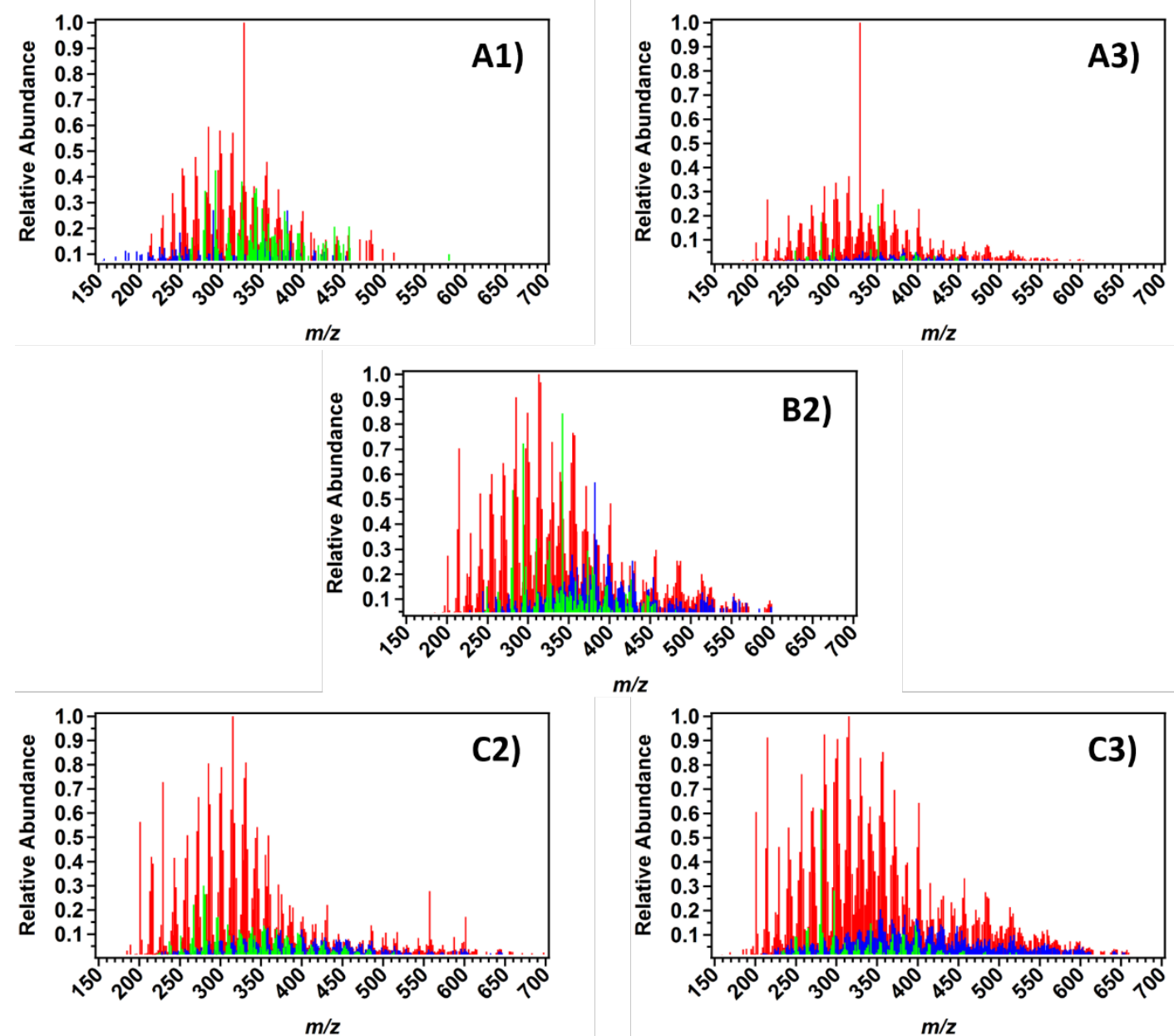

B2)
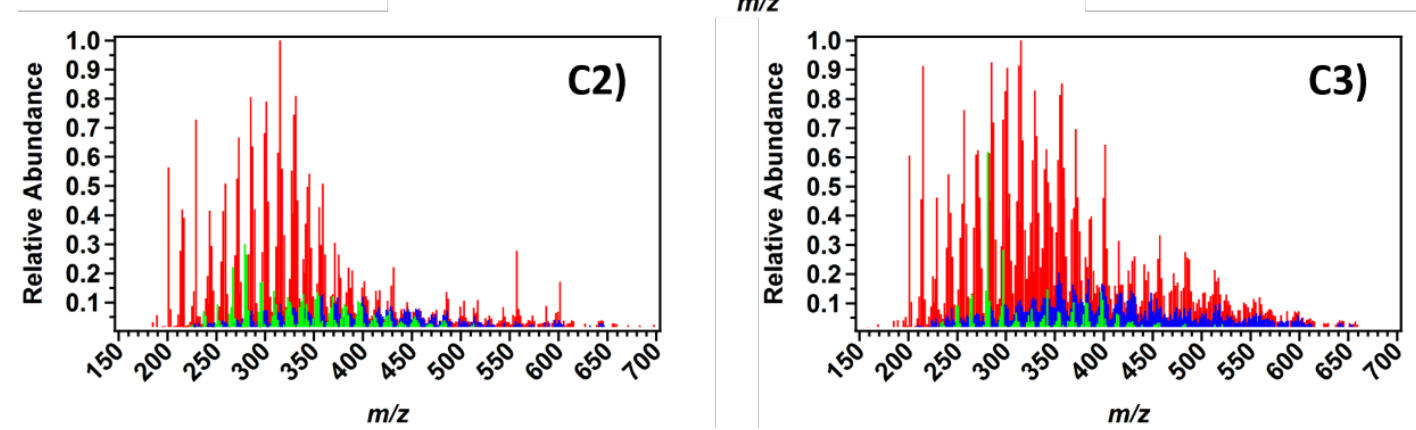

77 Fig. S2. Reconstructed ESI-FTICR-MS negative ion mass spectra of compound types (CHO, $78 \mathrm{CHNO}$, CHOS, and CHNOS) for cloud water samples collected during biogenic influence 79 (A1 and A3), urban influence (B2), and Canadian wildfire influence (C2 and C3). 

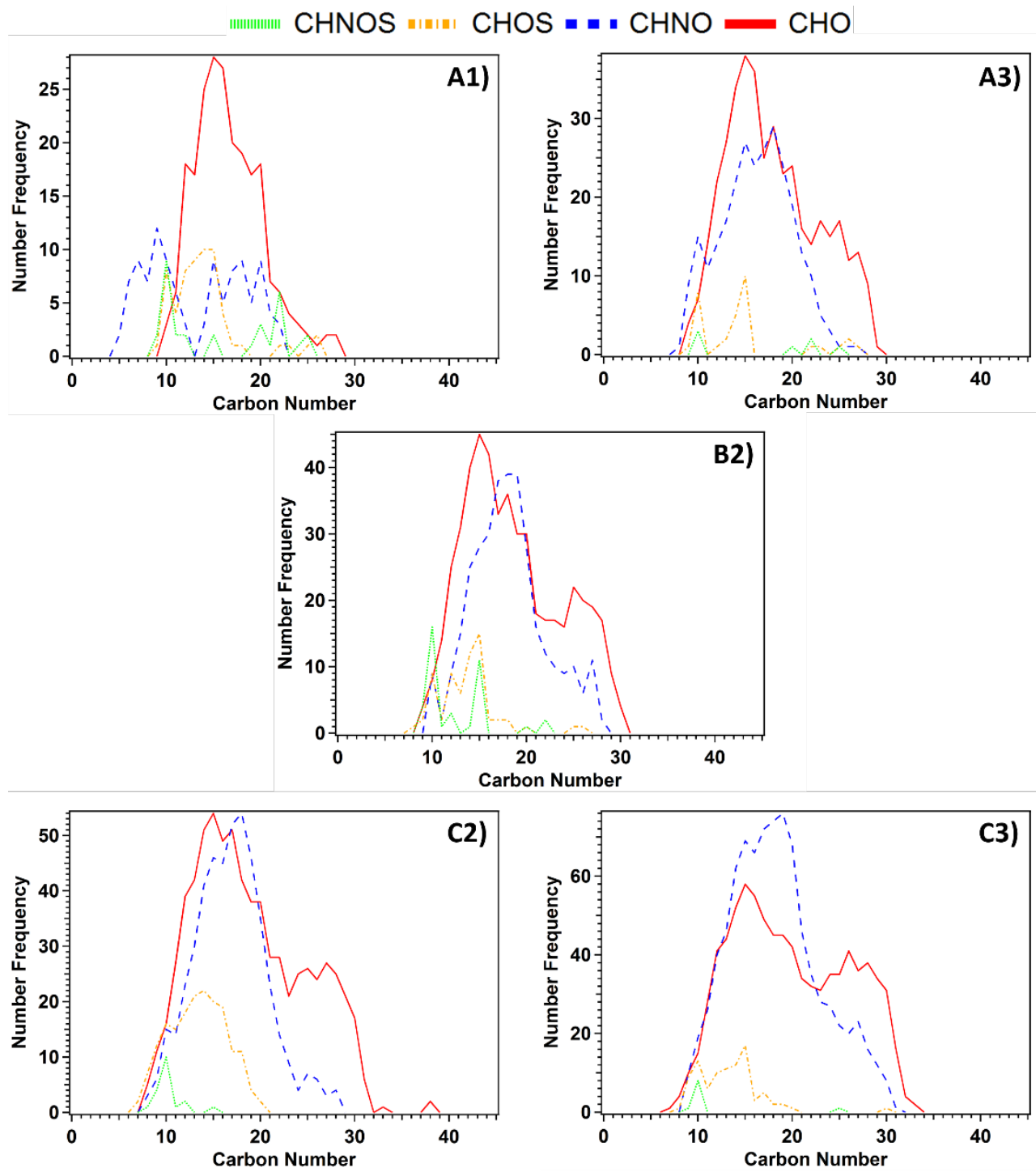

81 Fig. S3. Carbon number frequency distribution of organic compounds identified in cloud

82 water collected during biogenic (A1 and A3), urban (B2), and wildfire (C2 and C3)

83 influences. 

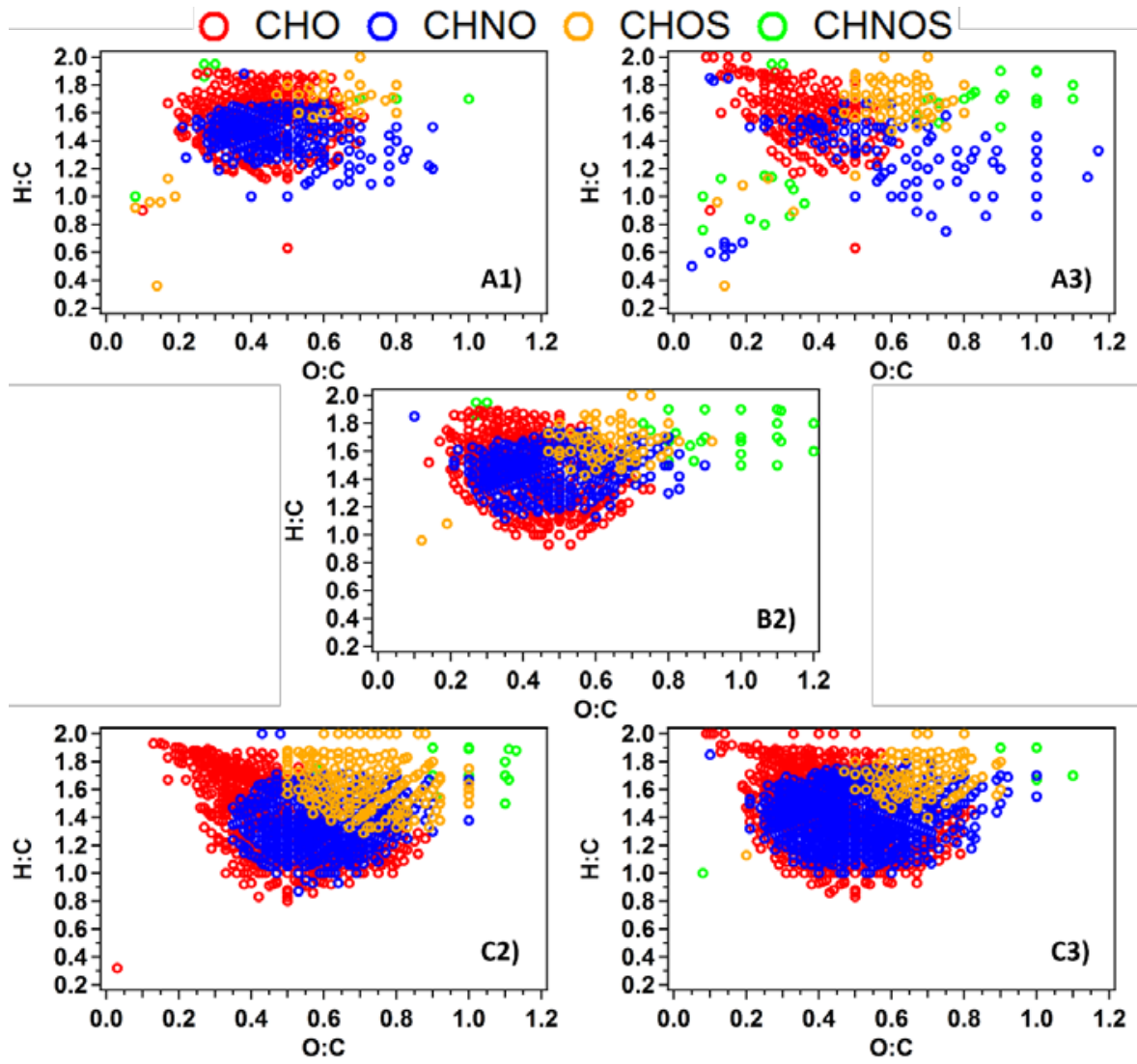

O:C

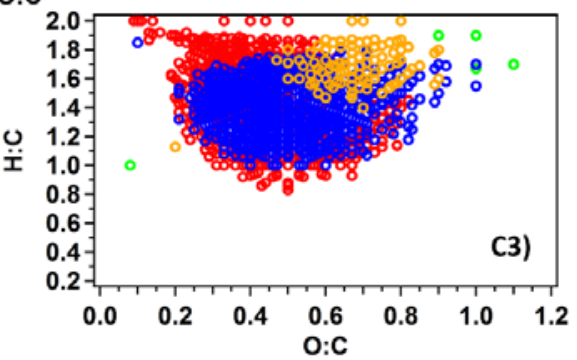

85 Fig. S4. Van Krevelen diagrams for the identified negative ions for the cloud water samples

86 collected on (A1) 08/16/2014 18:00, (A3) 08/17/2014 18:00, (B2) 09/02/2014 18:00, (C2)

87 08/05/2014 06:00, and (C3) 08/06/2014 18:00 

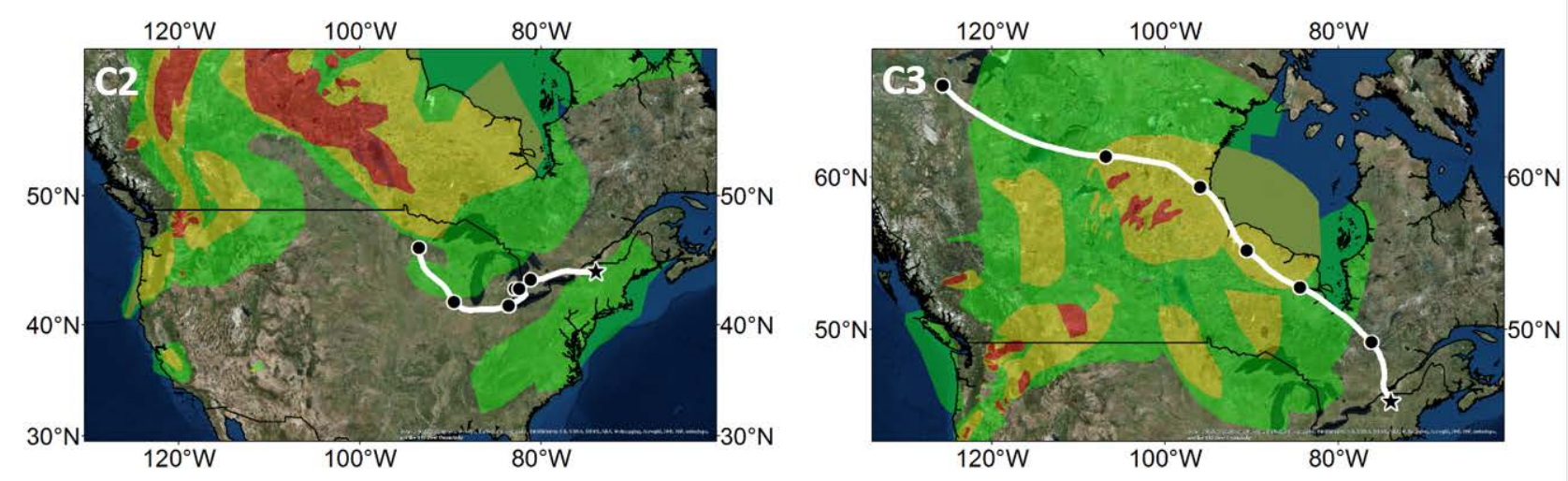

CHNO, $34 \pm 1 \%$

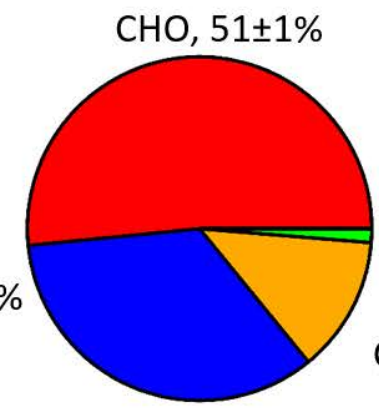

CHNOS, $1.4 \pm 0.3 \%$

CHOS, $12.9 \pm 0.8 \%$

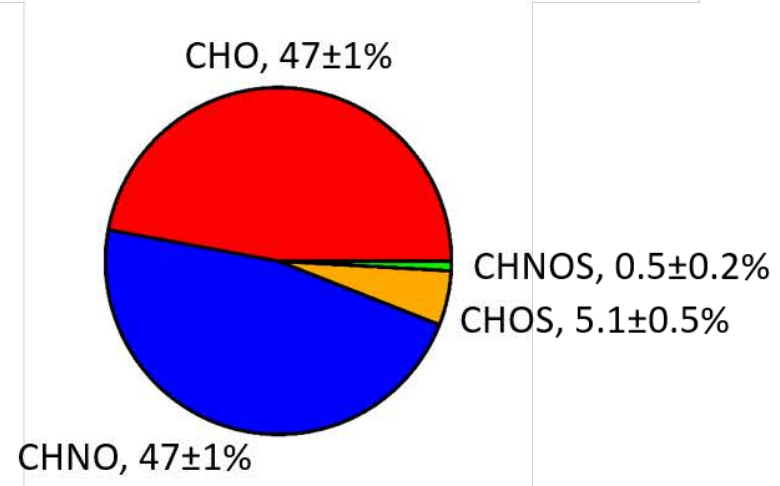

88 Fig. S5. NOAA HYSPLIT 144 h (6 day) backward air mass trajectories (white lines, with 6 h

89 resolution shown as black dots) and corresponding changes in cloud water molecular

90 composition, shown as compound type number percentages during the wildfire event

91 (samples C2 and C3). Green, yellow, and red shading on the maps represent low, moderate,

92 and high amounts of smoke, respectively, as defined by the NOAA Hazard Mapping System

93 Fire and Smoke Product (http://www.ospo.noaa.gov/Products/land/hms.html). 


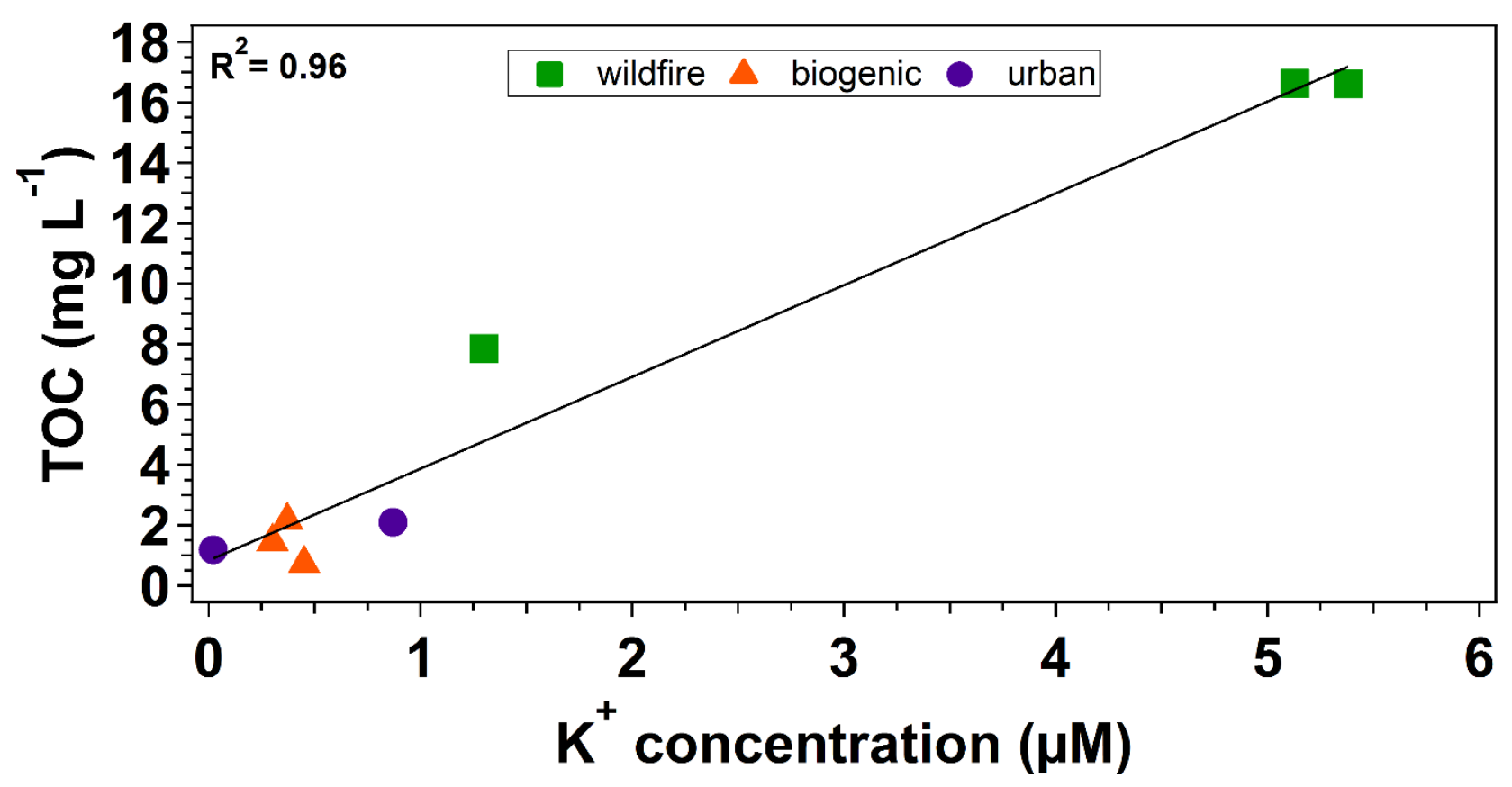

94

95 Fig. S6. Correlation between cloud water total organic content (TOC) and $\mathrm{K}^{+}$concentration 96 for each sample, categorized by air mass source influence. 